ORNL/ TM-2004/ 291

\title{
Frequency Regulation Basics and Trends
}

\section{December 2004}

Brendan J . Kirby 


\section{DOCUMENT AVAILABILITY}

Reports produced after January 1, 1996, are generally available free via the U.S. Department of Energy (DOE) Information Bridge.

Web site http://www.osti.gov/bridge

Reports produced before January 1, 1996, may be purchased by members of the public from the following source.

National Technical Information Service

5285 Port Royal Road

Springfield, VA 22161

Telephone 703-605-6000 (1-800-553-6847)

TDD 703-487-4639

Fax 703-605-6900

E-mail info@ntis.fedworld.gov

Web site http://www.ntis.gov/support/ordernowabout.htm

Reports are available to DOE employees, DOE contractors, Energy Technology Data Exchange (ETDE) representatives, and International Nuclear Information System (INIS) representatives from the following source.

Office of Scientific and Technical Information

P.O. Box 62

Oak Ridge, TN 37831

Telephone 865-576-8401

Fax 865-576-5728

E-mail reports@adonis.osti.gov

Web site http://www.osti.gov/contact.html

This report was prepared as an account of work sponsored by an agency of the United States Government. Neither the United States government nor any agency thereof, nor any of their employees, makes any warranty, express or implied, or assumes any legal liability or responsibility for the accuracy, completeness, or usefulness of any information, apparatus, product, or process disclosed, or represents that its use would not infringe privately owned rights. Reference herein to any specific commercial product, process, or service by trade name, trademark, manufacturer, or otherwise, does not necessarily constitute or imply its endorsement, recommendation, or favoring by the United States Government or any agency thereof. The views and opinions of authors expressed herein do not necessarily state or reflect those of the United States Government or any agency thereof. 
ORNL/TM-2004/291

\section{FREQUENCY REGULATI ON BASI CS AND TRENDS}

Brendan J. Kirby

December 2004

Prepared by

OAK RIDGE NATIONAL LABORATORY

P.O. Box 2008

Oak Ridge, Tennessee 37831-6283

managed by

UT-Battelle, LLC

for the

U.S. DEPARTMENT OF ENERGY under contract DE-AC05-00OR22725 



\section{Contents}

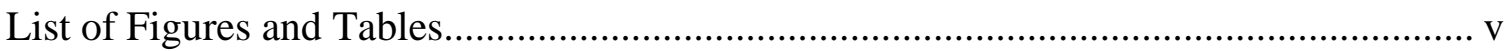

Abbreviations and Acronyms ................................................................................... vii

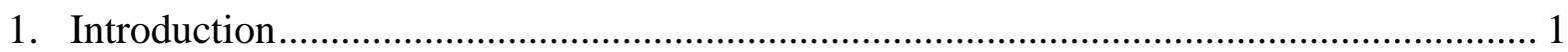

2. Ancillary Services for Power System Reliability ........................................................ 3

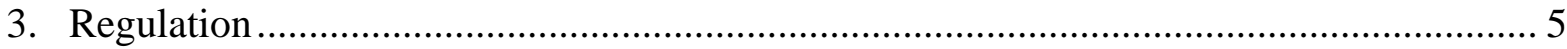

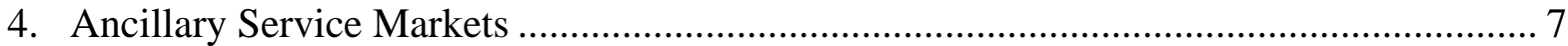

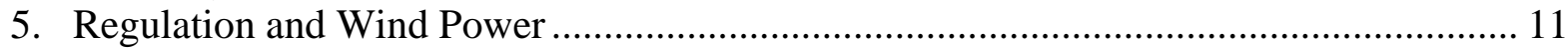

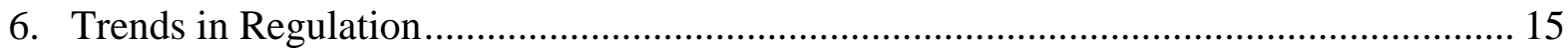

Renewable Portfolio Standards and Distributed Generation .................................... 15

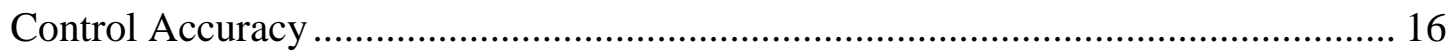

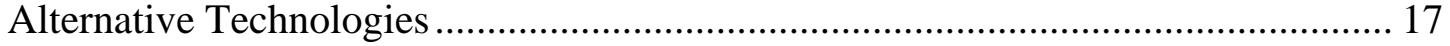

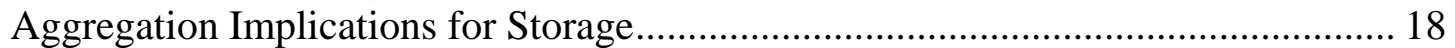

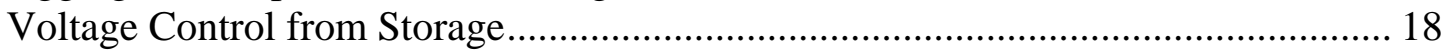

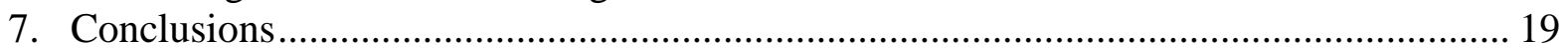

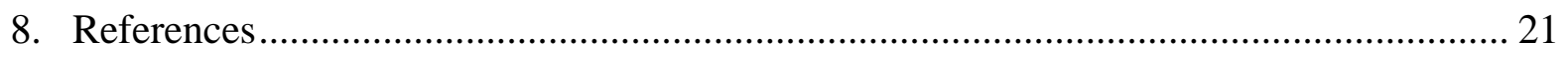





\section{List of Figures and Tables}

\section{Figures}

1. Governor response and contingency reserves successfully restored the generation and load balance after the loss of $2600 \mathrm{MW}$ of generation

2. Contingency reserves provide a coordinated response to the sudden loss of generation or transmission........................................................................... 4

3. The response time frame distinguishes ancillary services. ...................................... 4

4. Regulation is a zero-energy service that compensates for minute-tominute fluctuations in total system load and uncontrolled generation. .......................... 5

5. Regulation price is dominated by the energy opportunity cost of the

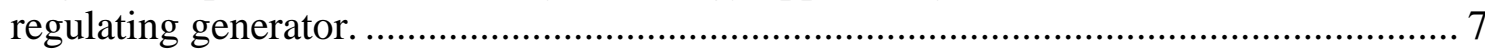

6. California’s average hourly ancillary service prices for 2002 show

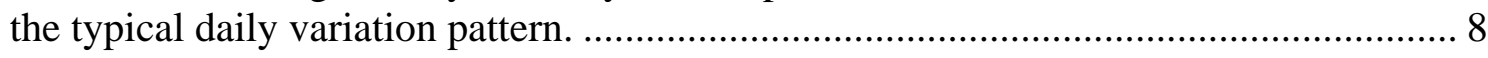

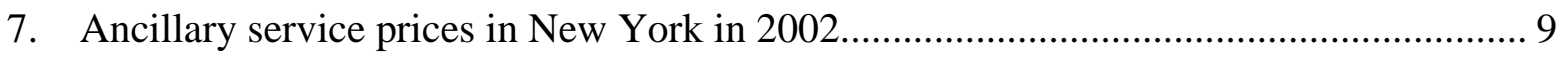

8. Two days of output and wind speed from a four-section midwestern wind plant......

9. Correlation among wind turbine power fluctuations varies with both

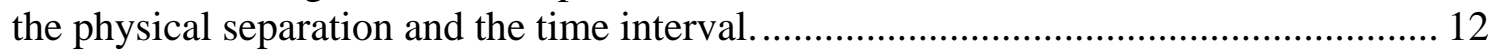

10. Coal-fired generators do not follow regulation signals precisely ............................... 16

\section{Tables}

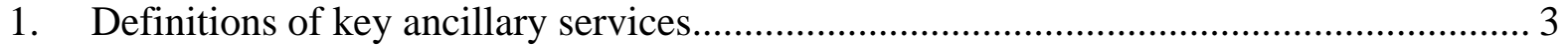

2. Comparison of regulation and load following characteristics ..................................... 6

3. Average ancillary service prices (per megawatt-hour) from several markets ................. 9

4. Characteristics of four-section midwestern wind plant ............................................ 11

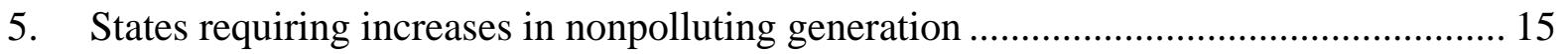

6. Industrial loads that could supply regulation ....................................................... 17

7. Energy storage characteristics required to provide regulation versus load following 



\section{Abbreviations and Acronyms}

ACE area control error

AGC automatic generation control

CHP combined heat and power

CPS Control Performance Standard (NERC)

DCS Disturbance Control Standard (NERC)

DG distributed generation

ERCOT Electric Reliability Council of Texas

FERC Federal Energy Regulatory Commission

ISO independent system operator

NERC North American Electric Reliability Council

RPS renewable portfolio standards

T\&D transmission and distribution 



\section{Introduction}

The electric power system must address two unique requirements: the need to maintain a near real-time balance between generation and load, and the need to adjust generation (or load) to manage power flows through individual transmission facilities. These requirements are not new: vertically integrated utilities have been meeting them for a century as a normal part of conducting business. With restructuring, however, the services needed to meet these requirements, now called "ancillary services," are being more clearly defined. Ancillary services are those functions performed by the equipment and people that generate, control, and transmit electricity in support of the basic services of generating capacity, energy supply, and power delivery. The Federal Energy Regulatory Commission (FERC) has defined such services as those "necessary to support the transmission of electric power from seller to purchaser given the obligations of control areas and transmitting utilities within those control areas to maintain reliable operations of the interconnected transmission system.” This statement recognizes the importance of ancillary services for both bulk-power reliability and support of commercial transactions.

Balancing generation and load instantaneously and continuously is difficult because loads and generators are constantly fluctuating. Minute-to-minute load variability results from the random turning on and off of millions of individual loads. Longer-term variability results from predictable factors such as the daily and seasonal load patterns as well as more random events like shifting weather patterns. Generators also introduce unexpected fluctuations because they do not follow their generation schedules exactly and they trip unexpectedly due to a range of equipment failures. The output from wind generators varies with the wind.

Storage technologies should be ideal suppliers of several ancillary services, including regulation, contingency reserves (spinning reserve, supplemental reserve, replacement reserve), and voltage support. These services are not free; in regions with energy markets, generators are paid to supply these services. In vertically integrated utilities (without energy markets) the utility incurs significant costs to supply these services. Supplying these services may be a significant business opportunity for emerging storage technologies.

This report briefly explores the various ancillary services that may be of interest to storage. It then focuses on regulation, the most expensive ancillary service. It also examines the impact that increasing amounts of wind generation may have on regulation requirements, decreasing conventional regulation supplies, and the implications for energy storage. 



\section{Ancillary Services for Power System Reliability}

Ancillary services provide the resources the system operator requires to reliably maintain the instantaneous and continuous balance between generation and load. These services are briefly described in Table 1.

Table 1. Definitions of key ancillary services

\begin{tabular}{|c|c|c|c|}
\hline \multirow{2}{*}{ Service } & \multicolumn{3}{|c|}{ Service Description } \\
\hline & Response Speed & Duration & Cycle Time \\
\hline \multirow[t]{2}{*}{ Regulation } & \multicolumn{3}{|c|}{$\begin{array}{l}\text { Power sources online, on automatic generation control, that can respond rapidly to } \\
\text { system-operator requests for up and down movements; used to track the minute-to- } \\
\text { minute fluctuations in system load and to correct for unintended fluctuations in } \\
\text { generator output to comply with Control Performance Standards (CPSs) } 1 \text { and } 2 \text { of } \\
\text { the North American Reliability Council (NERC 2002) }\end{array}$} \\
\hline & $\sim 1 \min$ & Minutes & Minutes \\
\hline \multirow[t]{2}{*}{ Spinning reserve } & \multicolumn{3}{|c|}{$\begin{array}{l}\text { Power sources online, synchronized to the grid, that can increase output } \\
\text { immediately in response to a major generator or transmission outage and can reach } \\
\text { full output within } 10 \text { min to comply with NERC's Disturbance Control Standard } \\
\text { (DCS) }\end{array}$} \\
\hline & Seconds to $<10 \mathrm{~min}$ & 10 to $120 \mathrm{~min}$ & Days \\
\hline \multirow[t]{2}{*}{$\begin{array}{l}\text { Supplemental } \\
\text { reserve }\end{array}$} & \multicolumn{3}{|c|}{$\begin{array}{l}\text { Same as spinning reserve, but need not respond immediately; units can be offline } \\
\text { but still must be capable of reaching full output within the required } 10 \text { min }\end{array}$} \\
\hline & $<10 \min$ & 10 to $120 \mathrm{~min}$ & Days \\
\hline \multirow[t]{2}{*}{$\begin{array}{l}\text { Replacement } \\
\text { reserve }\end{array}$} & \multicolumn{3}{|c|}{$\begin{array}{l}\text { Same as supplemental reserve, but with a 30-min response time; used to restore } \\
\text { spinning and supplemental reserves to their pre-contingency status }\end{array}$} \\
\hline & $<30 \min$ & 2 hours & Days \\
\hline \multirow[t]{2}{*}{ Voltage control } & \multicolumn{3}{|c|}{$\begin{array}{l}\text { The injection or absorption of reactive power to maintain transmission-system } \\
\text { voltages within required ranges }\end{array}$} \\
\hline & Seconds & Seconds & Continuous \\
\hline
\end{tabular}

Three services — spinning reserve, supplemental reserve, and replacement reserve restore the generation and load balance in the event of a contingency such as the sudden, unexpected loss of a generator. Figure 1 provides an example of a contingency, and Fig. 2 shows how the three contingency reserves are coordinated to respond. Any resource that can respond quickly enough and for long enough can supply contingency reserves. Faster response has greater value to the power system. Ancillary services are distinguished by the time frame over which they operate, as shown in Fig. 3. 
Unlike the other ancillary services listed in Table 1, voltage control is not a real-power service. Instead, it involves the control of reactive power to maintain acceptable voltages throughout the power system under normal and contingency conditions. Dynamic reactive reserves respond quickly in the event of voltage transients that can lead to voltage collapse and are the most valuable to the power system.

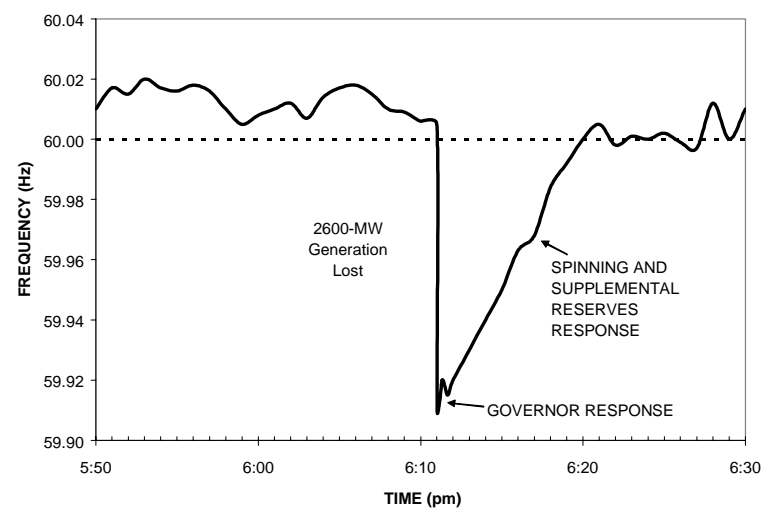

Fig. 1. Governor response and contingency reserves successfully restored the generation and load balance after the loss of 2600 MW of generation.

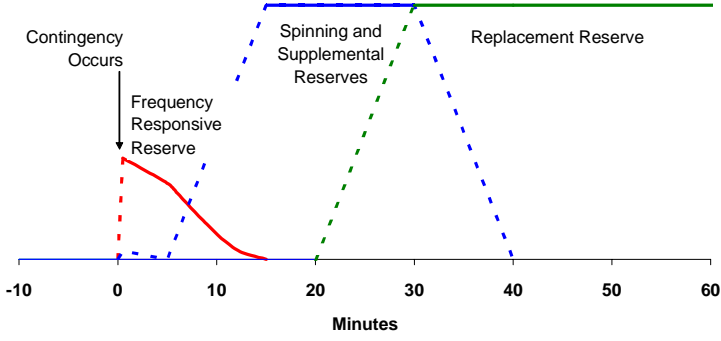

Fig. 2. Contingency reserves provide a coordinated response to the sudden loss of generation or transmission.

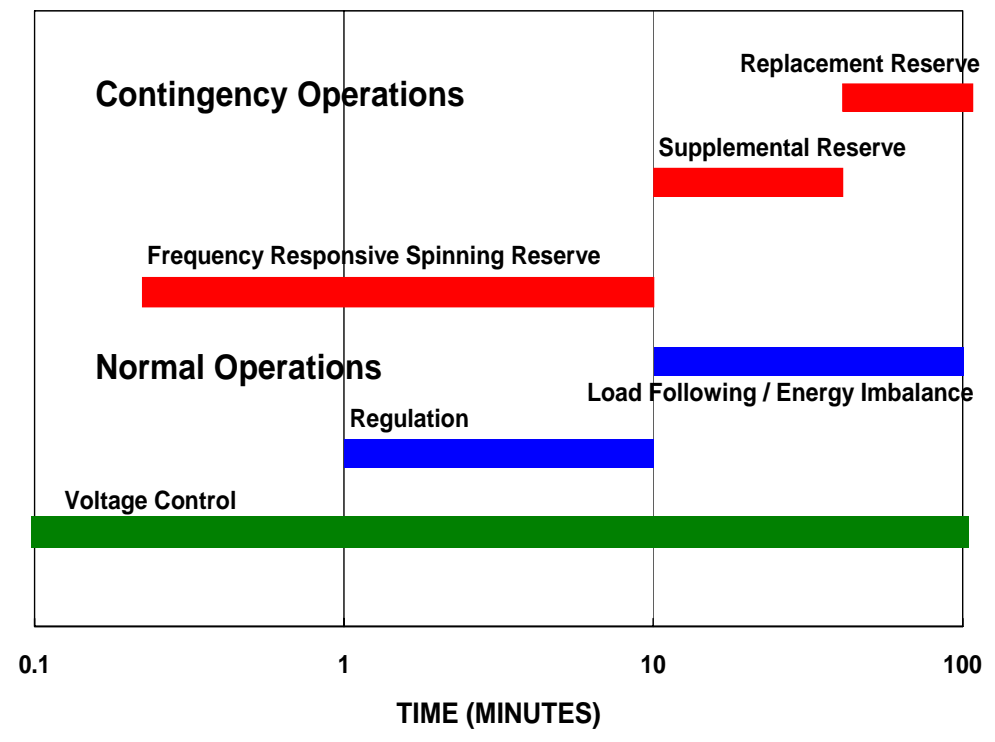

Fig. 3. The response time frame distinguishes ancillary services. 


\section{Regulation}

Regulation and load following (which, in competitive spot markets, are provided by the intra-hour workings of the real-time energy market) are the two services required to continuously balance generation and load under normal conditions (Kirby and Hirst 2000). Figure 4 shows the morning ramp-up decomposed into base energy, load following, and regulation. Starting at a base energy of $3566 \mathrm{MW}$, the smooth load following ramp is shown rising to $4035 \mathrm{MW}$. Regulation consists of the rapid fluctuations in load around the underlying trend, shown here on an expanded scale to the right with a $\pm 55 \mathrm{MW}$ range. Combined, the three elements serve a load that ranges from 3539 to 4079 MW during the three hours depicted.

In the PJM region, New York, New England, and Ontario, regulation is a 5 -min service, defined as five times the ramp rate in megawatts per minute. In Texas it is a 15-min service, and in Alberta and California it is a 10 -min service.

Load following and regulation ensure that, under normal operating conditions, a control

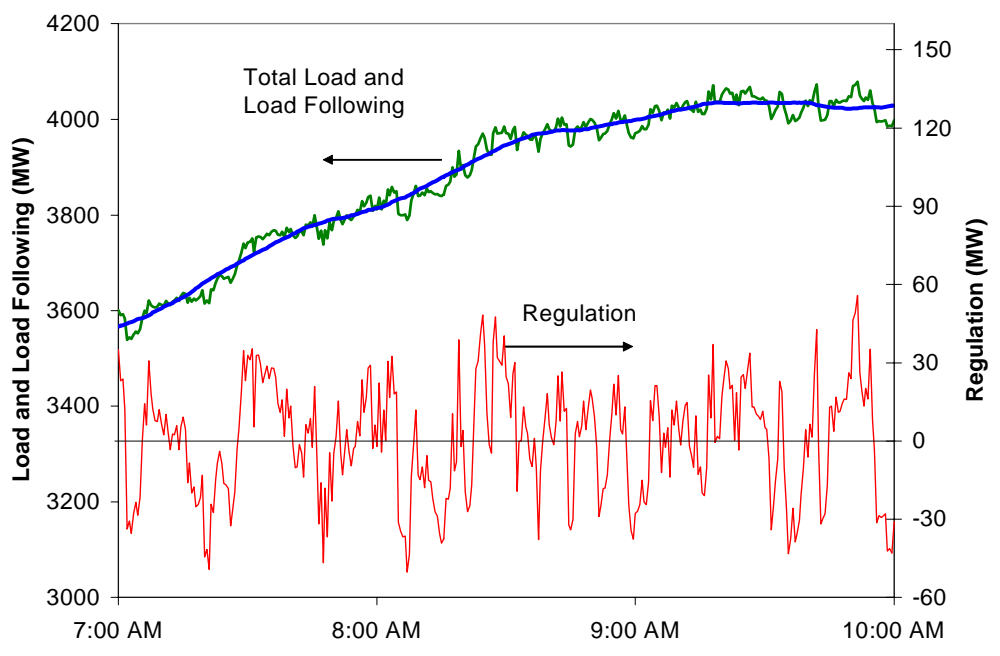

Fig. 4. Regulation is a zero-energy service that compensates for minute-to-minute fluctuations in total system load and uncontrolled generation. area is able to balance generation and load.

Regulation is the use of on-line generation, storage, or load that is equipped with automatic generation control (AGC) and that can change output quickly (MW/min) to track the moment-to-moment fluctuations in customer loads and to correct for the unintended fluctuations in generation. Regulation helps to maintain interconnection frequency, manage differences between actual and scheduled power flows between control areas, and match generation to load within the control area. Load following is the use of on-line generation, storage, or load equipment to track the intra- and inter-hour changes in customer loads. Regulation and load following characteristics are summarized in Table 2. 
Table 2. Comparison of regulation and load following characteristics

\begin{tabular}{lll}
\hline & Regulation & Load following \\
\hline Patterns & Random and uncorrelated & Highly correlated \\
Control & Requires AGC & Can be manual \\
Maximum swing & Small & $10-20$ times regulation \\
Ramp rate (MW/min) & $5-10$ times load following & Slow \\
Sign changes per unit time & $20-50$ times load following & Few \\
\hline
\end{tabular}

Control area operators do not need to specifically procure load following; it is obtained from the short-term energy market with generators (typically) responding to real-time energy prices. Regulation, however, requires faster response than can be obtained from units responding to market signals alone. Instead, generators (and potentially storage and/or responsive load) offer capacity that can be controlled by the system operator's AGC system to balance the power system.

Control areas are not able and not required to perfectly match generation and load. NERC has established the Control Performance Standard (CPS) to determine the amount of imbalance that is permissible for reliability purposes. CPS1 measures the relationship between the control area's area control error (ACE) ${ }^{1}$ and the interconnection frequency on a 1-min average basis. CPS1 values can be either "good" or "bad." When frequency is above its reference value, undergeneration benefits the interconnection by lowering frequency and leads to a good CPS1 value. Overgeneration at such times, however, would further increase frequency and lead to a bad CPS1 value. CPS1, although recorded every minute, is evaluated and reported on an annual basis. NERC sets minimum CPS1 requirements that each control area must exceed each year.

CPS2, a monthly performance standard, sets control-area-specific limits on the maximum average ACE for every 10-min period. Control areas are permitted to exceed the CPS2 limit no more than $10 \%$ of the time. This $90 \%$ requirement means that a control area can have no more than 14.4 CPS2 violations per day, on average, during any month.

Some storage technologies should be excellent regulation providers because this matches a zero net energy resource with a zero net energy service. The quick response and precise control offered by storage is also superior to the control capabilities of many conventional generators. Technologies that can perform repeated high cyclic storage without degradation in their performance will be best suited for regulation.

\footnotetext{
${ }^{1}$ The area control error is the difference between scheduled and actual net interchange with a bias included to help maintain scheduled system frequency.
} 


\section{Ancillary Service Markets}

Hourly markets for regulation and the contingency reserves (spinning, supplemental, and sometimes replacement reserves) exist or are being formed in most independent system operator (ISO) regions, including New England, New York, PJM (mid-Atlantic and Midwest), the Electric Reliability Council of Texas (ERCOT), California, Ontario, and Alberta. Such markets reveal value through prices. Markets, as opposed to long-term contracts, are advantageous because a resource's ability (and cost) to supply each of these services varies as its position in the hourly energy market varies.

Direct costs for generators supplying regulation, for example, include a degraded heat rate and increased wear and tear on the unit. The dominant expense, however, is the lost opportunity cost associated with maneuvering the generator in the energy market so that it has capacity available to sell in the regulation market. For example, a 600-MW generator with a full power energy production cost of \$15/MWh would have to bid $\$ 27 / \mathrm{MWh}$ of regulation if the energy market were clearing at \$30/MWh. This is to compensate the generator for the lost profit in the energy market when it reduces output in order to create maneuvering room to supply regulation and to compensate for the reduced efficiency (increased heat rate) associated with the remaining output's still being sold into the energy market. Figure 5 shows how a generator's cost (and bid price) to supply regulation depends upon the current energy price (Hirst

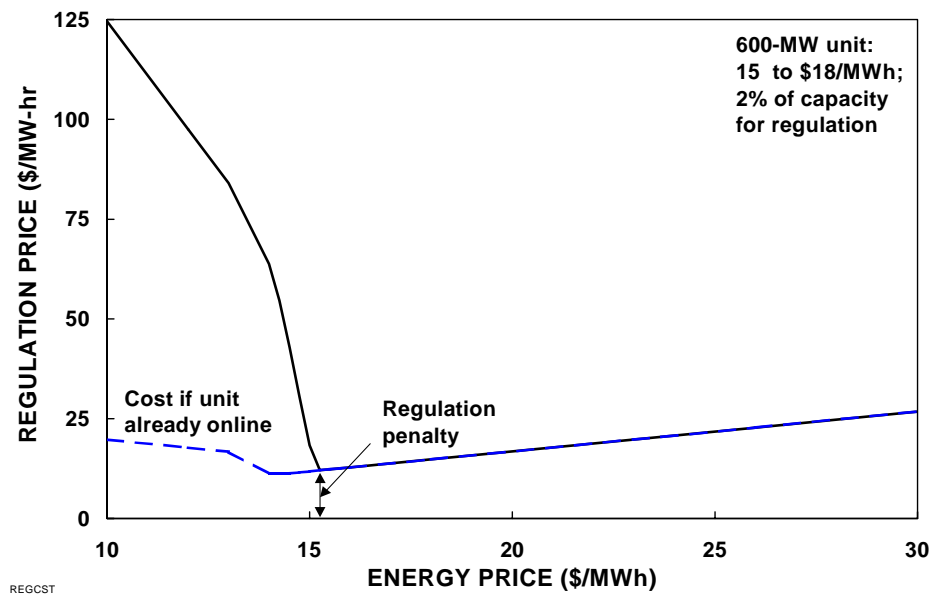

Fig. 5. Regulation price is dominated by the energy opportunity cost of the regulating generator. and Kirby 1997). Note too that this generator is limited to supplying only about $12 \mathrm{MW}$ of regulation ( $2 \%$ of its rated capacity). This is because regulation is a quick service; and the unit ramp rate, rather than the total available capacity, limits the peak amount of regulation it can provide. For this reason regulation is generally spread across several generators.

There is also an opportunity cost when the energy market price is below the generator's marginal production cost. When energy prices are low (typically at night) and generators are at minimum load, they incur a cost for running above minimum load in order to 
supply down regulation. For example, a generator with a 150-MW minimum load and an energy production cost of $\$ 18 / \mathrm{MWh}$ would have to bid $\$ 64 / \mathrm{MWh}$ of regulation if the energy market were clearing at \$14/MWh because it would be losing \$4 for each $162 \mathrm{MWh}$ it must sell into the energy market to get its base operating point high enough to provide room to regulate down. Opportunity costs similarly dominate contingency reserve prices.

The relationship between ancillary service costs and lost opportunities in the energy markets results in volatile ancillary service prices. Figure 6 shows how ancillary service prices vary on average throughout the day in California. Not surprisingly, the faster response services command higher prices. Also not surprisingly, prices for contingency reserves vary hourly and show a daily pattern that mirrors the daily fluctuation of energy prices. Prices for regulation remain high at night, however, because regulation requires that suppliers be able to move down as well as up. Downward capacity is scarce at night when most generation is lightly loaded.

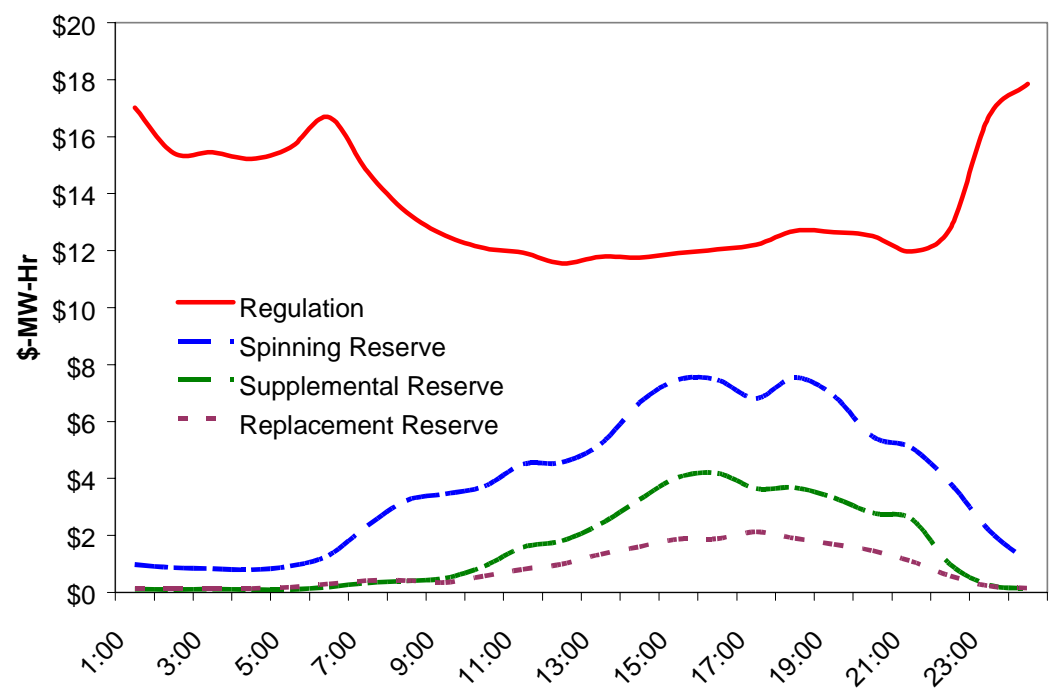

Fig. 6. California's average hourly ancillary service prices for 2002 show the typical daily variation pattern. California separates up and down regulation, so that comparable prices in other markets are twice as high.

Ancillary services are predominantly capacity services rather than energy services. When a generator supplies regulation, it moves above and below a base operating point. The base energy it is supplying is not related to regulation but is necessary because generators have minimum load levels. This energy is sold into the energy market. The energy component of the regulation service itself nets out to zero energy over a few hours as the generator maneuvers around the base operating point. Storage can supply regulation without the need to be simultaneously supplying a basic amount of energy. A storage project can vary its output around zero - acting as a generator at times and acting as a load at other times. The energy required to offset the turnaround efficiency penalty could be purchased by the storage project from the energy market or could be supplied to the project by the system operator. This added cost is similar to a generator's added cost 
associated with the degraded heat rate that comes from rapidly controlling the unit. These added costs are one reason that regulation is the most expensive ancillary service.

Table 3 compares average hourly ancillary service prices from several markets.

Regulation, which requires continuous and rapid control, commands the highest price up to ten times the price of spinning reserve. Spinning reserve prices are typically twice the price of supplemental reserve. Based upon price, the faster response services are more attractive services for storage to supply. The shorter deployment times are also better matched to the capabilities of many storage systems. However, the high cycling requirements associated with regulation may limit some storage technologies; hence, the duty cycle must be considered.

Table 3. Average ancillary service prices (per megawatt-hour) from several markets

\begin{tabular}{lccccc}
\hline & New York & PJM & California & ISO-NE & Alberta \\
\hline Regulation & $\$ 28.32$ & $\$ 38.94$ & $\$ 36.43^{a}$ & $\$ 38.80$ & $\$ 35$ \\
Spinning reserve & 3.04 & - & 3.89 & - & 30 \\
Supplemental reserve & 1.51 & - & 1.57 & - & 17 \\
Replacement reserve & 1.23 & - & 0.86 & - & - \\
\hline
\end{tabular}

Note: When available, 2003 prices are presented; otherwise, prices are from 2002.

${ }^{a}$ California purchases up and down regulation separately. The combined price is shown here.

Ancillary service prices are typically volatile. As Fig. 7 shows, contingency reserve prices are frequently modest but are occasionally quite high for regulation and spinning reserves (NYISO 2003). When generators are on line but not fully loaded, their cost (and hence their bid prices) for providing contingency reserves can be nearly zero. When generation is scarce,

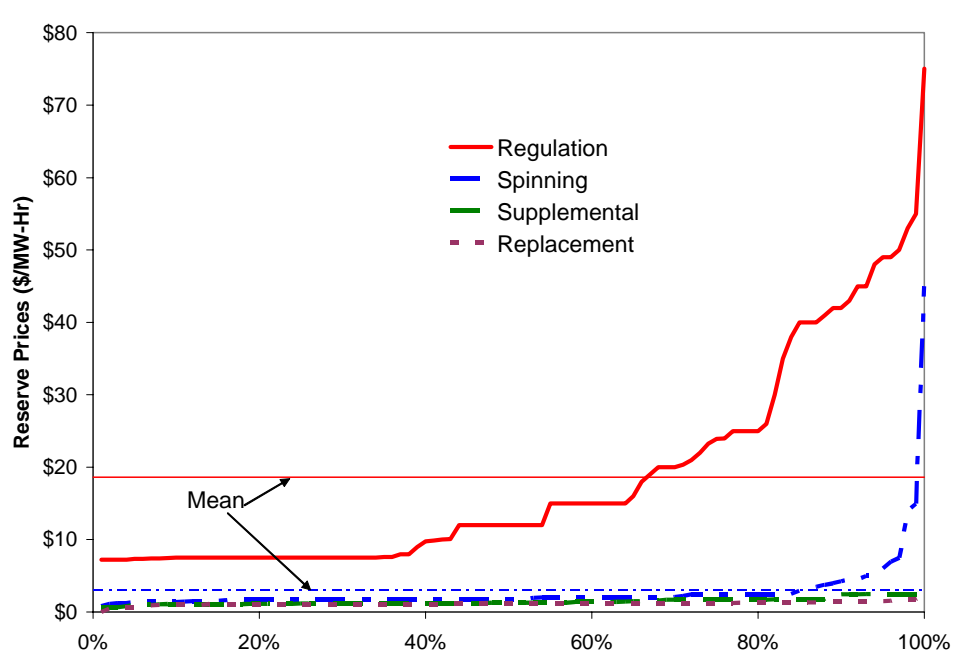

Fig. 7. Ancillary service prices in New York in 2002. however, capacity is expensive and lost opportunity costs are high. Regulation prices show a more gradual price rise because regulation must come from generators with both head room and foot room; the generators have to be within their operating range rather than at the bottom. 



\section{Regulation and Wind Power}

As a result of varying wind conditions, wind facilities generate varying amounts of electricity. From a grid operations perspective, other generation resources must offset these changes in output. Figure 8 shows variations in wind speed and power output from a midwestern wind plant (Hudson, Kirby, and Wan, 2001). Output from this plant is monitored in four sections, labeled A, B, C, and D. As shown in Table 4, each interconnection point has a different number of turbines. Volatility in the wind speed as well as the output from each of the four sections and the total plant output is readily apparent.

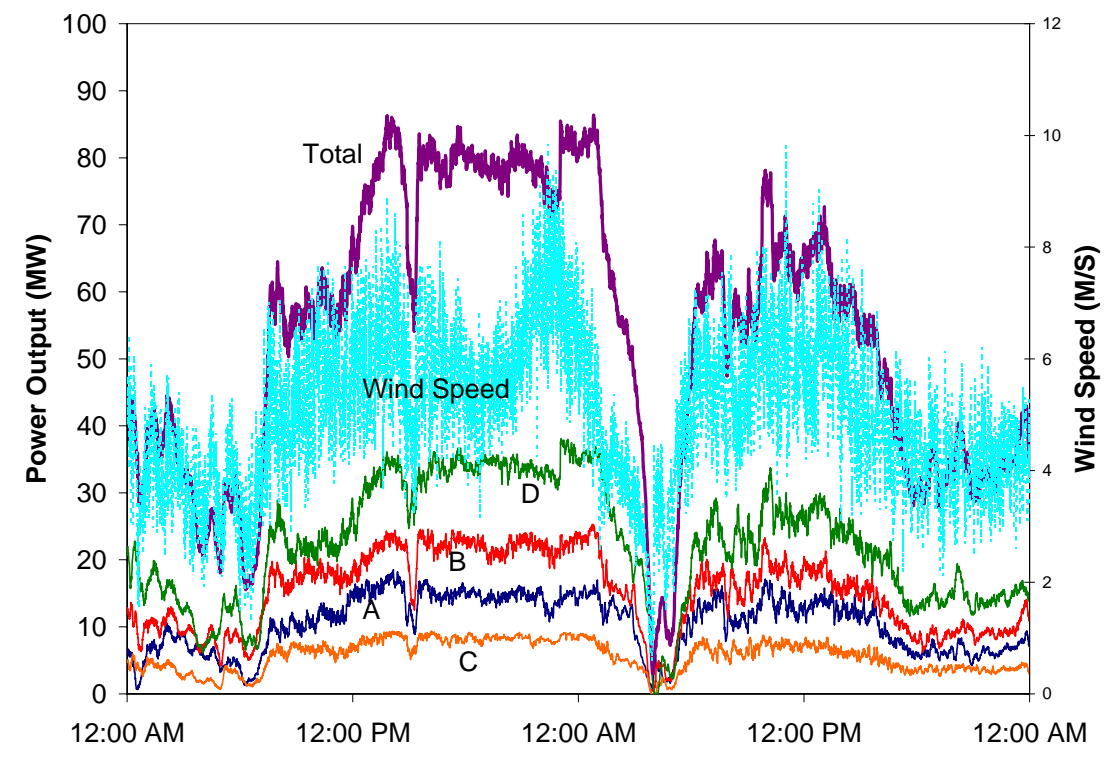

Fig. 8. Two days of output and wind speed from a four-section midwestern wind plant.

Table 4. Characteristics of four-section midwestern wind plant

\begin{tabular}{lcccccc}
\hline & \multicolumn{4}{c}{ Interconnection point } & \\
\cline { 2 - 5 } & A & B & C & D & Total \\
\hline Number of turbines & 30 & 39 & 14 & 55 & 138 \\
MW rating & 23 & 29 & 10 & 41 & 103 \\
Stand-alone regulation requirement (MW) & 1.8 & 2.2 & 1.0 & 2.5 & $4.8^{a}$ \\
Control area regulation allocation (MW) & - & - & - & - & 0.8 \\
\hline
\end{tabular}

${ }^{a}$ The value is 4.8 MW for the total wind plant vs 7.5 MW for the sum of A through D individually. 
Things are not quite as bad as they at first seem, however. Wind plants benefit greatly from aggregation. Wind turbines are spread over a large area, even within each section of the wind plant. Not all turbines encounter the same wind speed fluctuations at the same time. The result of connecting many turbines at independently fluctuating power levels is that the variability of the combined output is less than the variability of any equivalent single turbine. The 138 turbines in this midwestern wind plant are spread over 11 miles. When a wind gust sweeps through the wind plant, it reaches some turbines sooner than others. Power output fluctuations are not completely independent, but they are not completely correlated either. The degree of correlation depends on the time scale being examined, with faster fluctuations (regulation) being less correlated than slower fluctuations (load following and energy production), as shown in Fig. 9 (Ernst, Wan, and Kirby 1999). The 4.8 MW of stand-alone regulation capacity required by this wind plant is about $65 \%$ of the $7.5 \mathrm{MW}$ of regulation that would be required if the four sections were to address regulation independently. Had the four sections of this wind plant behaved completely independently, in the regulation time frame, they would only have required 3.9 MW of regulation.

As discussed above, relative regulation requirements decrease whenever larger aggregations are considered. For example, consider a 100-MW wind plant that is integrated into a 2300-MW host control area. Providing regulation for the aggregation, as opposed to providing it for each of the individuals, reduces the total regulation requirement and benefits everyone. In this case, the host control area regulation requirement is $30 \mathrm{MW}$

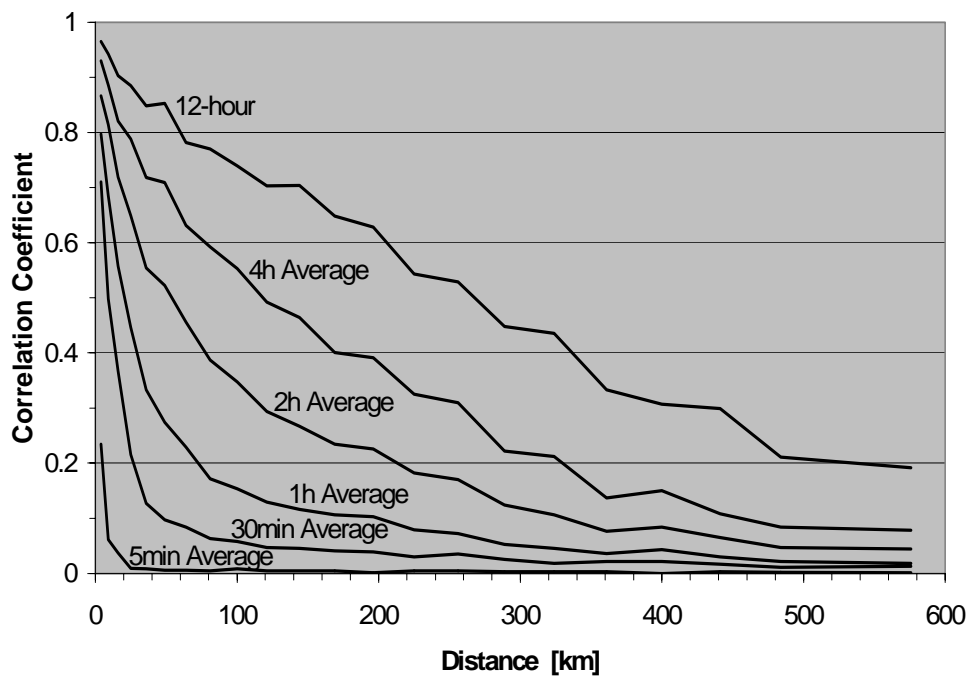

Fig. 9. Correlation among wind turbine power fluctuations varies with both the physical separation and the time interval.

(about $2 \%$ of the average

energy requirement). Including the wind plant raises the aggregate regulation requirement to $30.4 \mathrm{MW}$. Allocating the aggregate regulation requirement back to the control area load and wind plant reduces the load obligation of the control area to 29.6 MW and the obligation of the wind plant to $0.8 \mathrm{MW}$ in this case, an $84 \%$ reduction for the wind plant. A larger 202-MW wind plant would have required 18.2 MW of regulation during a particularly volatile week if it had to compensate for its variability independently but would require only 9.4 MW when integrated into this control area, a $48 \%$ reduction for the wind plant. The control area loads would benefit as well because, though the total 
regulation requirement would increase to $35.1 \mathrm{MW}$, the load's allocation would drop to 25.6 MW. Aggregation is a powerful tool for reducing regulation requirements that benefits all participants. As seen in the above example, the benefit is particularly strong for smaller entities (Kirby and Hirst 2000; Hudson, Kirby, and Wan 2001). 



\section{Trends in Regulation}

\section{Renewable Portfolio Standards and Distributed Generation}

Renewable portfolio standards (RPS) in several states are calling for significant increases in nonpolluting generation within the next few years, as shown in Table 5 (Deyette 2004). Wind is likely to be the generation technology of choice in meeting many of these standards because of the low cost and relative maturity of the technology.

\section{Table 5. States requiring increases in nonpolluting generation}

\begin{tabular}{llc}
\hline State & Required increase & By \\
\hline Arizona & $8.1 \%$ & 2012 \\
California & $20 \%$ & 2017 \\
Connecticut & $7 \%$ & 2010 \\
Hawaii & $20 \%$ & 2020 \\
Maryland & $7.5 \%$ & 2019 \\
Minnesota & $825 \mathrm{MW}+10 \%$ & 2015 \\
New Jersey & $6.5 \%$ & 2012 \\
New Mexico & $10 \%$ & 2019 \\
New York & $25 \%{ }^{a}$ & 2012 \\
Texas & $2000 \mathrm{MW}(\sim 3 \%)$ & 2009 \\
Wisconsin & $2.2 \%$ & 2011 \\
\hline \multicolumn{2}{l}{${ }^{a}$ New York already obtains 17\% of its energy from } \\
hydropower.
\end{tabular}

Increasing levels of wind penetration will have larger impacts on regulation requirements. A wind plant with a stand-alone regulation requirement that is $10 \%$ as large as that of the rest of the control area will increase the total control area regulation requirement by $0.5 \%$. If the regulation requirement of a larger wind plant is equal to that of the rest of the control area (an extremely large collection of wind plants), the total control area regulation requirement will increase by $41 \%$. The aggregation benefit reduces the impact by $59 \%$ (41\% instead of doubling) but still a significant increase (Kirby and Hirst 2000).

Increasing wind generation may also reduce the regulation capacity of the control area. This is because increasing wind generation will necessarily reduce the contribution from other generation if the load remains constant. The displaced generation is likely to be the marginal generation that is least economical to run (as opposed to the lowest-cost baseload generation). This displaced marginal generation is also the generation that has maneuvering capability and often supplies regulation to the power system.

Increases in distributed generation (DG) have similar impacts on power system regulation capability. While distributed generators typically do not impose additional regulation burdens, they are typically not capable of supplying regulation themselves. Microturbines do not follow load well. Distributed generators that are coupled with heat recovery 
devices for combined heat and power (CHP) can achieve excellent efficiencies but are further restricted by their thermal loads from varying their output to provide regulation. As with wind, the utility generators that DG displaces are often the marginal units that supply regulation economically.

\section{Control Accuracy}

Generators differ dramatically in how well they follow the system operator's commands to supply regulation (Kirby and Hirst 2000). Hydropower units typically track control signals quite well, while thermal units have more difficulty. This is one reason that the amount of regulation required by two control areas of similar size can differ substantially. The quality of the available regulation resources can differ, and consequently, the amount of regulating resources (MW) that must be deployed to obtain similar satisfactory reliability performance differs. Figure 10 compares the requested and actual regulation movements for two large coalfired generators. Generator $\mathrm{A}$ is considered to be fairly good (for a coal burner) at regulating. Generator B is clearly not very good. But there are no metrics for regulation provision. All regulation providers are paid on the basis of the capacity they supply, not on the performance of that capacity. At most, system operators reserve the right to disqualify a generator from providing regulation if performance degrades too badly. This is not sustainable in the long term. Regulation prices will have to distinguish among suppliers on the basis of the quality of regulation supplied. Perhaps "effective regulation" will be measured and paid for. When such distinctions can be measured, regulation providers with precisely controllable resources will receive higher payments than those available in today's regulation markets.
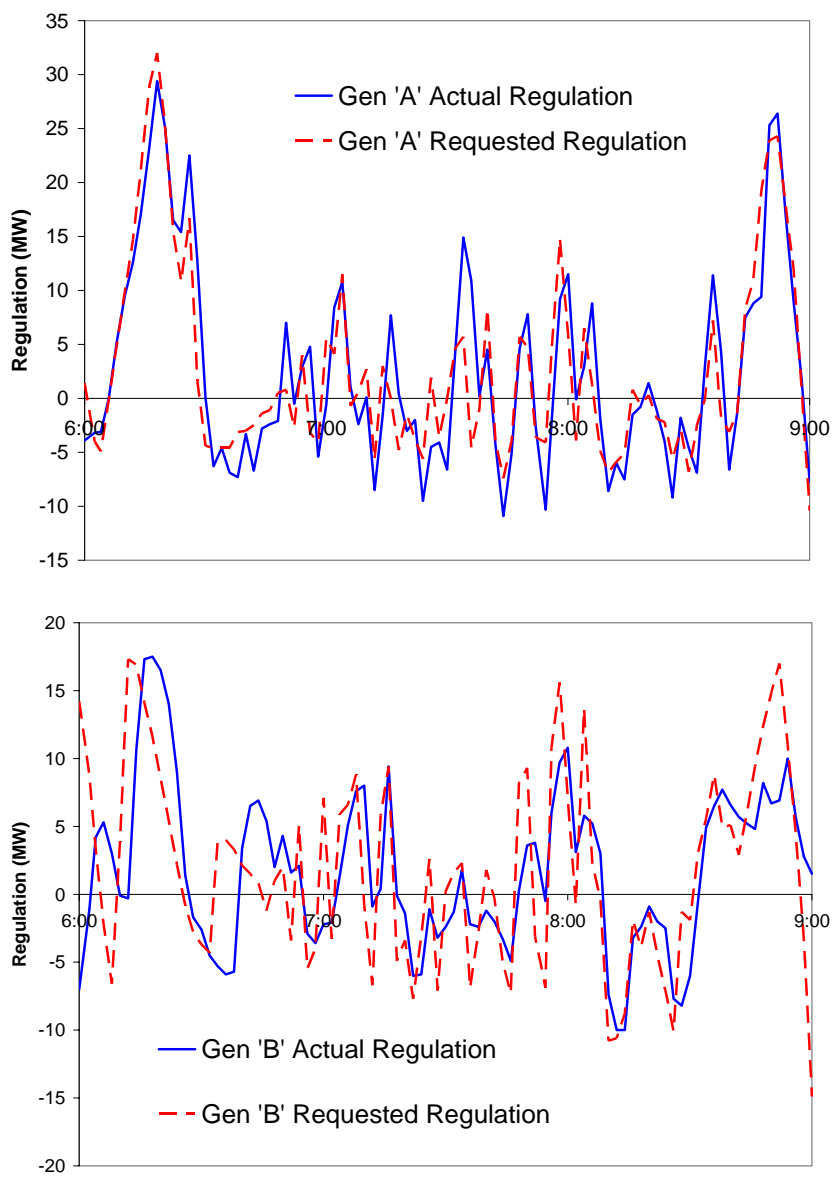

Fig. 10. Coal-fired generators do not follow regulation signals precisely. Some (e.g., Generator $A$ in the top graph) do better than others (e.g., Generator B, bottom). 
Interestingly, the requirements for power delivery out of storage supplying regulation will depend upon the size of the storage project. A relatively small storage project (compared to the total regulation requirement of the control area) will likely spend all the time either charging or discharging at full power. A larger storage project will carefully control the ramp rate for charging and discharging. This is because the storage project will likely be the lowest marginal cost, fastest responding, best controlled regulating resource. Hence it will be the first resource used by the system operator. If the storage project is small in comparison to the total regulating requirements of the control area then the control area will always be calling for more control than the project can supply (Figure 4) and the control system will be calling for either full charge or full discharge. If, on the other hand, the storage project's capabilities are similar in size to the control area's needs, then the control system will be calling for the exact amount of charging or discharging power needed each minute and will only rarely call for the full power capabilities of the project.

\section{Alternative Technologies}

Other technologies have the potential to supply regulation. Some loads could supply regulation by rapidly varying their power consumption. Chlor-alkali production, aluminum, and air liquefaction are candidates, as shown in Table 6. Current regional reliability council rules prohibit loads from supplying regulation, and none are attempting to do so at this time. It will be difficult for most loads to give as much continuous control to an outside entity (the system operator), as is required to provide regulation for a function other than the load's primary business. Loads (especially air conditioning and water pumping loads) could be excellent suppliers of spinning reserve, however, and may eventually play a significant role in that market.

Table 6. I ndustrial loads that could supply regulation

\begin{tabular}{lc}
\multicolumn{1}{c}{ Load type } & $\begin{array}{c}\text { Total U.S. MW load } \\
\text { (MW) }\end{array}$ \\
\hline Air liquefaction & 1,000 \\
Induction \& ladle metallurgy furnaces & 1,000 \\
Gas \& water pumping with variable-speed & NA $^{a}$ \\
motor drives & \\
Electrolysis: & 14,000 \\
$\quad$ Aluminum & 6,500 \\
Chlor-alkali & 4,500 \\
Potassium hydroxide & 1,000 \\
Magnesium, sodium chlorate, copper & $\mathrm{NA}^{a}$ \\
\hline
\end{tabular}

${ }^{a}$ Not available.

Wind turbines themselves could supply regulation, or at least reduce their own regulation burden. Fast control of the turbine blades could spill energy to rapidly control the output for downward regulation swings. Blades could be returned to their optimal position during upward regulation swings. While this potential is technically exciting, the 
necessity to reduce average output coupled with the low marginal cost of wind generation means that the opportunity cost to provide regulation directly from wind should be relatively high even compared to the current method of regulation with generators where the higher fuel-based energy cost reduces the opportunity cost for regulation. In comparison with these options, storage should be the better economic choice.

\section{Aggregation I mplications for Storage}

The high price of regulation coupled with the good match between the technical capabilities of some storage technologies and the requirements of the power system make regulation an attractive market for storage projects. The strong aggregation effects exhibited by regulation have two important implications for storage projects. First, it is always cheaper to provide regulation to the control area rather than to compensate for the variability of individual loads directly. That is, it takes fewer regulating resources to meet reliability requirements if those resources respond to the control area's overall fluctuations as opposed to responding directly to the fluctuations of individual loads and wind plants. This reduces the amount of regulation, and consequently storage, required. Second, the reduced amount of storage that is required may be a benefit for developers of storage technologies because it increases the affordable price per unit of storage capability. The 103-MW wind plant given as an example in Section 5 does not need to obtain $5 \mathrm{MW}$ of storage to mitigate the regulation impact it is having on the power system; it need only obtain $1 \mathrm{MW}$ and allow that storage to be controlled by the power system operator to counter overall control area power fluctuations.

\section{Voltage Control from Storage}

Voltage control is not currently traded in hourly markets. It is more location-dependent than real-power regulation or contingency reserves and is typically procured through long-term contracts. Because reactive power losses are much greater than real power losses in the transmission and distribution (T\&D) grid, voltage-control equipment must be dispersed throughout the system and located close to where the voltage support is needed. This also means that competitive markets have typically not yet developed for obtaining voltage control, since there are too few potential suppliers at each location to compete. Instead, system operators install transmission equipment (tap changers, capacitors, reactors, static var compensators, etc.) to address voltage problems, and/or they obtain voltage support from local generators. In some places, the generators are paid for this voltage support, while in others they are simply required to supply voltage support capability as a condition of interconnecting with the power system.

Some storage technologies with the appropriate four-quadrant power conversion system can be ideal suppliers of dynamic reactive power support and voltage support. Their power electronics interface enables them to operate as a static var compensator, with no impact on the real energy being stored. In locations where voltage control is required, energy storage owners may be compensated for such voltage control. 


\section{Conclusions}

Power system reliability depends upon the ancillary services that system operators obtain to maintain generation and load balance under normal and contingency conditions. These services have always been required, but with restructuring they are more precisely defined. More importantly, markets now set prices for these services and reveal their value. Prices are volatile because they predominantly depend upon the lost opportunities of generators that could sell into the energy market if they were not providing balancing services. This same dependence means, however, that regulation prices will trend with energy price and are not likely to go down. Prices are highest for the fastest service, regulation, which involves tracking the minute-to-minute fluctuations in customer loads and unintended fluctuations in generation.

Regulation is a zero-energy service, making it an ideal candidate for supply by storage. Table 7 compares the characteristics required for an energy storage device to provide regulation and load following. As can be seen clearly in Fig. 4, providing regulation requires the storage device to charge and discharge many times per hour. Cycle life is critical. Providing load following, however, requires only one to two cycles per day. Similarly, high ramp rates are required for regulation but not for load following. Altogether, these requirements result in a stored energy requirement for load following that is 200 to 2000 times greater than what is required for regulation. The differing service requirements have implications for the storage technologies supplying each service. Flywheels and supercapacitors, with their high cycle life and ramping capabilities, are good candidates for regulation. Batteries may be better for supplying load following, where cycle life requirements and the ratio of peak power to stored energy are lower.

Table 7. Energy storage characteristics required to provide regulation versus load following

\begin{tabular}{lll}
\hline & Regulation & Load following \\
\hline Cycle life (20-year) & 500,000 & $3,000-10,000$ \\
Round trip efficiency & High & Less critical \\
Response time & $>1$ minute & $>1$ hour \\
Power delivery duration & $10-15$ min & $2-10$ hours \\
Service duty & Continuous & Hours between cycles \\
Potential technologies & Flywheels & Flow batteries \\
& Ultra capacitors & CAES \\
\hline
\end{tabular}


Once regulation markets mature, the almost perfect control exhibited by storage devices should command higher prices than the poor control exhibited by large thermal power plants. The same power electronics interface that enables storage devices to provide precise regulation control can often also provide dynamic voltage control. Markets do not yet exist for dynamic voltage control because of the reduced geographic scope of reactive power, but system operators enter into long-term contracts for its provision.

The proliferation of renewable portfolio standards and the maturing of wind technology (with decreasing costs, higher availability, and greater reliability) is resulting in increased amounts of wind power. One of the few drawbacks to wind is the unpredictability and variability of the power output. Aggregation, both among wind turbines within wind plants and with the overall control area load, greatly reduces the regulation impact. Still, wind power does increase regulation needs. Wind also displaces conventional generation, often the marginal generators that provide regulation. The increase in distributed generation and cogeneration similarly displace marginal conventional generation with resources that are unable to supply regulation. These factors will increase the need for new technologies to supply regulation. 


\section{References}

Deyette, J. 2004. jdeyette@ucsusa.org, www.ucsusa.org/energy, July.

Ernst, B., Y. Wan, and B. Kirby. 1999. Short-Term Power Fluctuation of Wind Turbines: Looking at Data from the German 250-MW Measurement Program from the Ancillary Services Viewpoint, Windpower '99 Conference, American Wind Energy Association, Washington, DC, June.

Hirst, E., and B. Kirby. 1997. Creating Competitive Markets for Ancillary Services, ORNL/CON-448, Oak Ridge National Laboratory, Oak Ridge TN, October.

Hudson, R., B. Kirby, and Y. Wan. 2001. Regulation Requirements for Wind Generation Facilities, American Wind Energy Association, June.

Kirby, B., and E. Hirst. 2000. Customer-Specific Metrics for the Regulation and LoadFollowing Ancillary Services, ORNL/CON-474, Oak Ridge National Laboratory, Oak Ridge, TN, January.

Kirby, B., and E. Hirst. 2001. "Real-Time Performance Metrics for Generators Providing the Regulation Ancillary Service,” Electricity Journal, April.

NYISO (New York Independent System Operator). 2003. www.nyiso.org, New York Independent System Operator, Albany, NY.

NERC (North American Electric Reliability Council). 2002. NERC Operating Manual, Princeton, NJ, November 21. 
